\title{
DESAFIOS DO TRANSPORTE DE GLP PARA O ESCOAMENTO DO POLO URUCU DURANTE A VAZANTE DA BACIA AMAZÔNICA
}

\author{
Jorge Luiz do Carmo ${ }^{1}$ \\ Márcio Braguez Aragão
}

\section{RESUMO}

O Polo Urucu é um complexo petrolífero localizado em uma área remota da floresta amazônica. Não há dutos para escoar a produção de petróleo e gás liquefeito de petróleo (GLP) para os mercados consumidores. O transporte do GLP produzido no local é feito por uma frota de navios especializados. As condições de navegabilidade dos rios são fortemente influenciadas pelos períodos de enchente e vazante anuais. Este artigo analisa os desafios logísticos do transporte aquaviário para o escoamento de GLP do Polo Urucu durante a estiagem na região Norte do país e nos países fronteiriços ao estado do Amazonas, período no qual os níveis de água da bacia Amazônica caem drasticamente, restringindo sobremaneira a navegação com segurança na região.

Palavras-chave: Vazante rio Amazonas, operação Codajás, transporte de GLP, Polo Urucu, Província Petrolífera de Urucu

\section{CHALLENGES OF LPG TRANSPORTATION FOR RELIEF OF URUCU POLE DURING THE EBB OF AMAZON BASIN}

\begin{abstract}
Urucu Pole is an oil complex located in a remote area of the Amazon rainforest. There are no pipelines to transport oil and liquefied petroleum gas (LPG) production to consumer markets. The LPG produced on site is transported by a fleet of specialized vessels. The navigability conditions of rivers are strongly influenced by the periods of annual flood and ebb. This paper analyzes the logistical challenges of waterway transport for the relief of LPG from the Urucu Pole during the drought in the North of the country and in the countries bordering the state of Amazonas, a period in which the water levels of the Amazon basin drop dramatically, greatly restricting the safe navigation in the region.
\end{abstract}

Keywords: Amazon river drought, Codajas ship-to-ship, LPG transportation, Urucu Pole, Urucu Petroleum Province

1 Analista de Transporte Marítimo da Petrobras. Graduado em Engenharia Mecânica pela Pontifícia Universidade Católica de Minas Gerais PUC/MG. Mestre em Comércio Internacional pela Universidad Isabel I de Castilla. Pós-graduando em Gerenciamento de Projetos pela Universidade Cândido Mendes. E-mail: jorgedocarmo58@yahoo.com.br

2 Analista de Transporte Marítimo da Petrobras. Oficial de Náutica, graduado em Ciências Náuticas pela Escola de Formação de Oficiais da Marinha Mercante - EFOMM. E-mail: mbaext@gmail.com 


\section{INTRODUÇÃO}

O Polo Urucu, também conhecido como a Província Petrolífera de Urucu, é um grande complexo petrolífero da Petrobras, cujas instalações de produção estão no meio da floresta amazônica. É localizado a aproximadamente $230 \mathrm{~km}$ de Coari e a $650 \mathrm{~km}$ de Manaus.

"O Polo Urucu compreende sete concessões de produção (Araracanga, Arara Azul, Carapanaúba, Cupiúba, Leste do Urucu, Rio Urucu, Sudoeste Urucu), todas localizadas no estado do Amazonas, nos municípios de Tefé e Coari." (AGÊNCIA PETROBRAS, 2020).

Figura 1 - Vista aérea de um dos polos da Província Petrolífera de Urucu

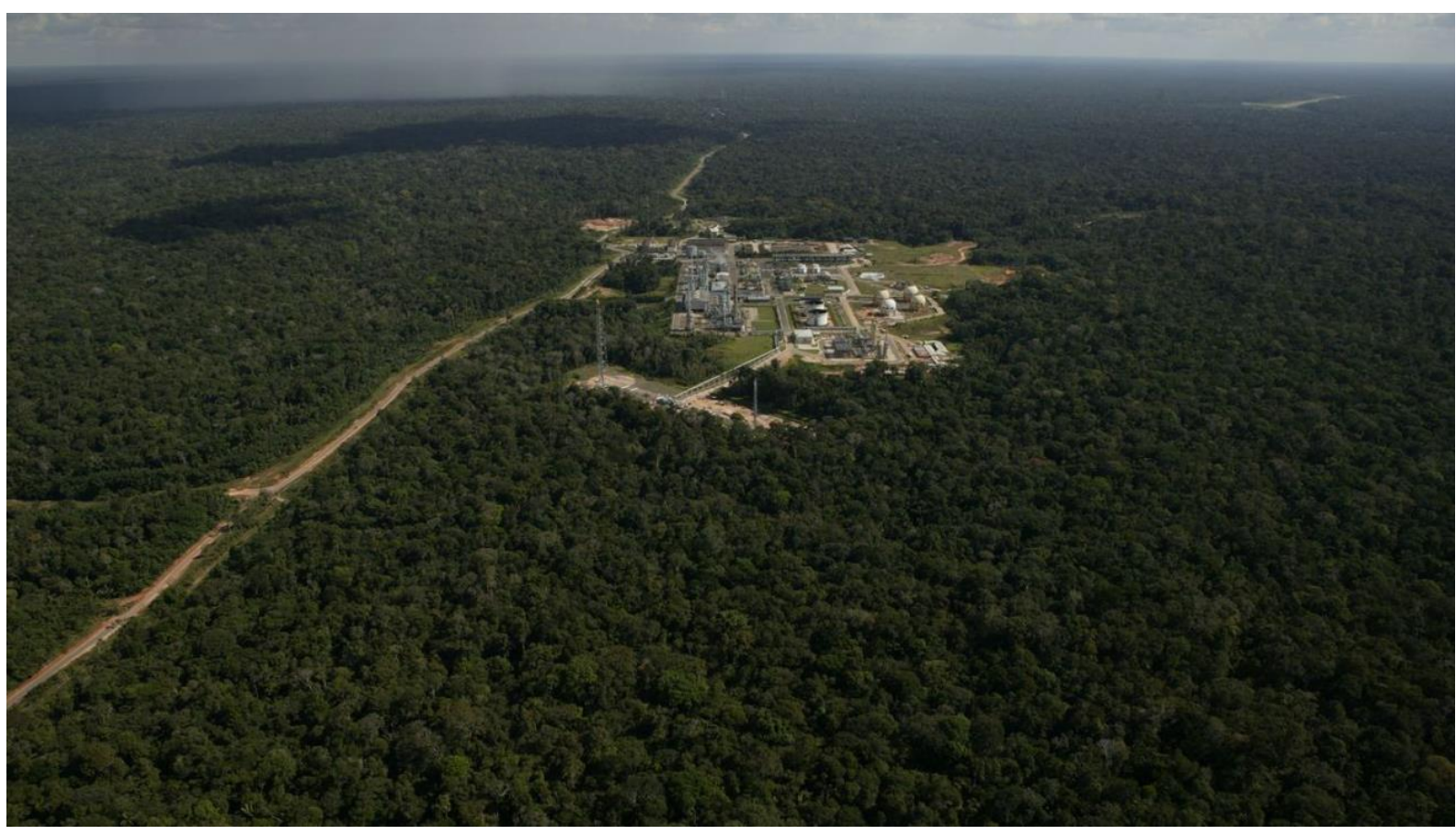

Fonte: AGÊNCIA BRASIL, 2016

No Polo Urucu, são produzidos petróleo, gás natural e gás liquefeito de petróleo (GLP) que precisam ser escoados para a continuidade da produção. O gasoduto Urucu-Coari-Manaus transporta o gás natural até a refinaria Isaac Sabbá, em Manaus. O escoamento de petróleo e GLP é feito através de transporte multimodal, combinando dutos e transporte hidroviário. Dutos levam petróleo e GLP do Polo Urucu 
até o Terminal Aquaviário de Coari (TA-Coari) onde são armazenados em esferas e tanques até o escoamento.

O transporte do petróleo é feito por conjuntos barcaças-empurradores. $\mathrm{O}$ foco deste trabalho é o transporte de GLP, que é feito através dos rios Solimões e Amazonas por uma frota de navios destinados ao transporte de gases liquefeitos de petróleo. Este escoamento é muito importante pois viabiliza a exploração contínua dos poços e garante o abastecimento dos mercados consumidores.

Os períodos de cheia e vazante influenciam fortemente a navegabilidade dos rios. Como o escoamento da produção de GLP deve ser contínuo e é realizado somente por via hídrica, um minucioso plano de contingência é elaborado para mitigar riscos logísticos durante a estiagem, advindos de uma possível interrupção na navegação devido à redução das profundidades nos trechos críticos

Este artigo tem como objetivo elencar e analisar os desafios do transporte de GLP durante a vazante na região Norte do país, quando as profundidades dos rios da bacia Amazônica caem drasticamente e o relevo submerso é alterado, dificultando a navegação e restringindo a capacidade de carga dos navios. Além disso, pretendemos estimular o debate ao apontar soluções e alternativas.

\section{A LOGÍSTICA DO ESCOAMENTO DA PRODUÇÃO DE GLP DO POLO URUCU}

O Polo Urucu produz 1.100 toneladas de GLP por dia, segundo a Agência Petrobras (2020). O gás produzido segue por um duto de $281 \mathrm{~km}$, que corta a floresta amazônica até o TA-Coari.

O TA-Coari está localizado na cidade de Coari, na margem direita do rio Solimões. Conforme a Transpetro (2020), o terminal possui 6 esferas de GLP com capacidade total de armazenagem de $18.000 \mathrm{~m}^{3}$. Um pier é dedicado a operações de GLP. Há restrições de calado, sendo 8,5 metros na cheia e 7 metros na vazante. O terminal possui uma régua para medir a profundidade local do rio Solimões.

O GLP produzido no Polo Urucu abastece os estados do Pará, Rondônia, Maranhão e parte do Ceará e Pernambuco.

As rotas de escoamento são : 
- Coari - Belém - Manaus - Coari

- Coari - São Luís - Manaus - Coari

- Coari - Belém - São Luís - Manaus - Coari

Uma vez carregado no TA-Coari, o navio desce o rio com sua velocidade aumentada devido à correnteza a seu favor, o que faz com que as 1385 milhas náuticas do trecho Coari-Belém sejam percorridas em aproximadamente 4 dias. $\mathrm{O}$ trecho Coari-São Luís, de 1566 milhas náuticas, é navegado em aproximadamente 5 dias. O tempo de viagem aumenta para 6 dias se o navio percorrer as 1858 milhas náuticas do trecho Coari-Belém-São Luís. Em todas as rotas foram consideradas velocidades médias de 13,5 nós.

$\mathrm{Na}$ viagem para novamente carregar no terminal, o navio está em lastro e enfrenta a correnteza contra. Ele faz obrigatoriamente escala em Manaus para, dentre outras atividades, abastecer, receber provisões, trocar tripulantes, e receber visitas da Agência Nacional de Vigilância Sanitária - ANVISA, Polícia Federal e Receita Federal. Além disso, o navio aguarda o horário certo de deixar Manaus para chegar em Coari próximo ao horário de atracar, já que no TA-Coari o fundeio é restrito e só permitido atracar durante o dia. O trecho Belém-Manaus-Coari, com 1405 milhas náuticas, é navegado em aproximadamente 4 dias. O trecho São Luís-Manaus-Coari, com 1586 milhas náuticas, é navegado em aproximadamente 5 dias. Nos dois trechos foram consideradas velocidades médias de 13,5 nós e não foram considerados os tempos de espera em Manaus.

Escoar a produção de forma contínua significa manter o Polo Urucu em funcionamento e os consumidores abastecidos. Uma falha na logística de escoamento da produção implicaria parada de produção por falta de espaço de armazenagem, gerando altos custos financeiros relativos à ociosidade do complexo petrolífero e à falha da entrega aos clientes.

A frota de navios gaseiros, como são chamados os navios especializados em transporte de gás liquefeito de petróleo, é dimensionada para atender as necessidades de carregamento de GLP no TA-Coari e entrega nos portos de Belém e São Luís, para distribuição aos clientes. A frota é composta por navios de diversos 
portes brutos, calados e capacidades de cargas. O porte bruto varia entre 3.000 a 9.000 toneladas. O calado varia entre 5 e 6,8 metros. A capacidade de carga varia entre aproximadamente 4.100 a $7.400 \mathrm{~m}^{3}$.

A programação de carga em Coari e escolha do navio para o transporte leva em consideração, dentre outras variáveis:

- quantidade de GLP disponível no terminal;

- disponibilidade do navio;

- capacidade de carga do navio;

- calado do navio;

- profundidade do rio Solimões;

- tempo de viagem.

Em Belém, a descarga de GLP é feita no Terminal Miramar, que pertence à Companhia Docas do Pará (CDP). O Terminal Miramar é muito importante, haja vista que movimenta todo o GLP consumido no Estado do Pará, além de abastecer o Estado do Amapá. A Transpetro ocupa uma área no terminal para operação e movimentação de combustíveis líquidos e gasosos. Segundo a Transpetro (2021), o terminal conta com 2 esferas para armazenagem de GLP, com capacidade nominal de $6.360 \mathrm{~m}^{3}$.

Em São Luís, a descarga de GLP é feita no Terminal de Itaqui, administrado pela Empresa Maranhense de Administração Portuária - EMAP. A Petrobras opera no terminal através de contrato de arrendamento. Segundo a Transpetro (2021a), a empresa conta com 2 esferas para armazenagem de GLP, com capacidade nominal de $4.800 \mathrm{~m}^{3}$. O GLP é descarregado no terminal, armazenado nas esferas e transferido para as distribuidoras instaladas no porto.

\section{A NAVEGAÇÃO DURANTE A VAZANTE DA BACIA AMAZÔNICA}

De acordo com a Agência Nacional de Águas e Saneamento Básico - ANA (2021), no Brasil há 12 regiões hidrográficas definidas pelo Conselho Nacional de Recursos Hídricos (CNHR). Uma região hidrográfica é formada por uma bacia, uma 
sub-bacia hidrográfica ou um grupo de bacias, que possuem semelhantes características naturais, sociais e econômicas.

A Região Hidrográfica Amazônica (RH Amazônica) ocupa 45\% do território nacional, abrangendo sete Estados (Acre, Amazonas, Rondônia, Roraima, Amapá, Pará e Mato Grosso). Possui uma extensa rede de rios com grande abundância de água, sendo os mais conhecidos: Amazonas, Xingu, Solimões, Madeira e Negro. (ANA, 2021).

Segundo a Agência Nacional de Transportes Aquaviários - ANTAQ (2021, apud ANA, 2011), a bacia Amazônica ocupa uma área de 6,1 milhões de $\mathrm{km}^{2}$, desde os andes peruanos até a foz do rio Amazonas, no Oceano Atlântico.

O rio Amazonas é o principal da bacia Amazônica. Ele nasce no Peru e recebe vários nomes até chegar ao Brasil, onde passa a ser chamado de rio Solimões. Em Manaus, ao juntar-se com o rio Negro, passa a ser chamado de rio Amazonas.

Segundo Salati et al. (1978), os índices de precipitação da região amazônica estão entre os mais altos do mundo. Conforme Ávila et al. (2019), em média, os índices pluviométricos da região amazônica estão próximos de $2.300 \mathrm{~mm}$ por ano, chegando até 5.000 mm por ano na Amazônia Ocidental.

Figura 2 - Região Hidrográfica Amazônica

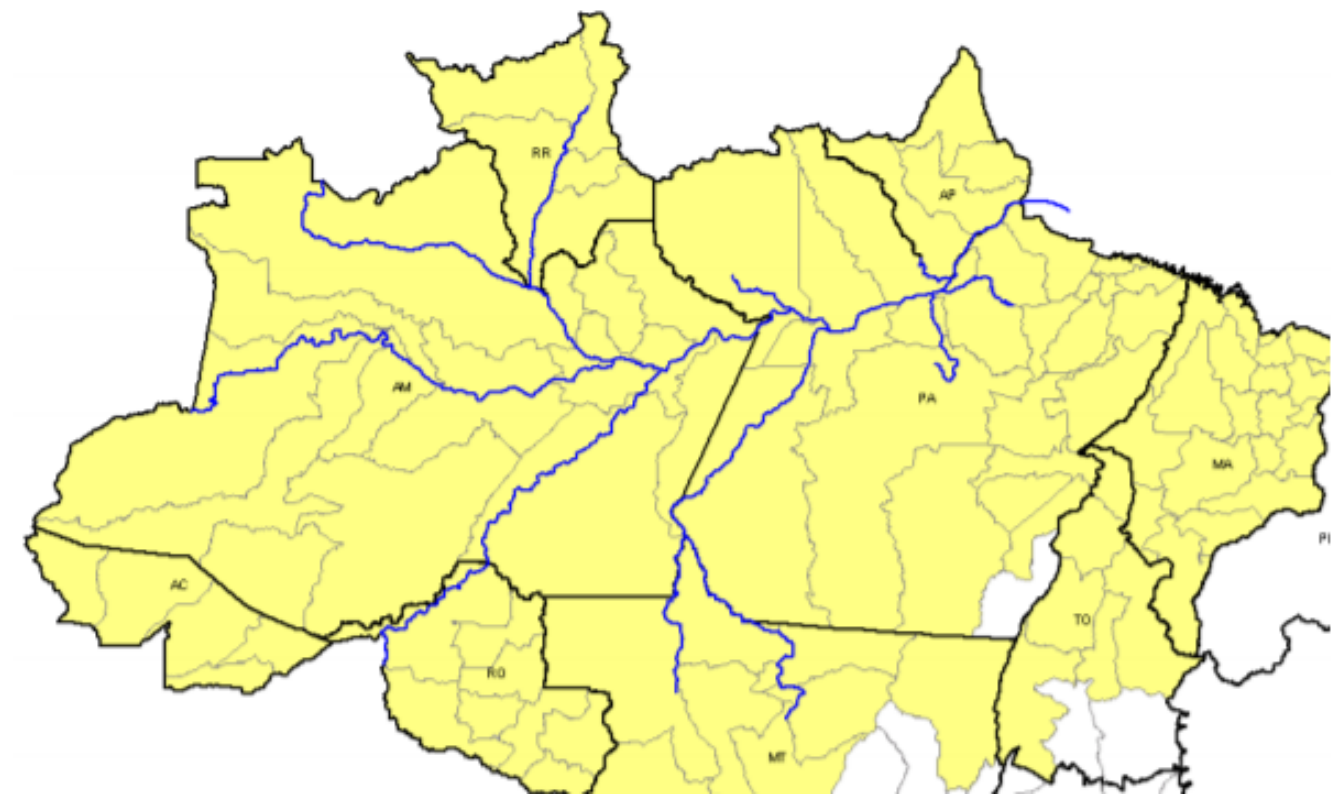

Fonte: ANTAQ (2021) 
De acordo com Fraxe et al. (2007), na várzea da Amazônia existem quatro "estações climáticas", sendo elas: enchente, quando o nível das águas sobe; cheia, quando o nível das águas atinge o seu limite máximo; vazante, quando o nível das águas desce; e seca, quando o nível das águas atinge o seu limite mínimo.

Como descreve Fisch et al. (2020), o período chuvoso na região Amazônica se dá entre os meses de novembro e março. O período de estiagem se dá entre os meses de maio a setembro. Abril e outubro são meses de transição entre o regime de chuvas e o período de seca.

Durante um período do ano, os rios da região oferecem algumas restrições à passagem das embarcações utilizadas para o transporte fluvial de cargas. Devido ao clima particular da região amazônica, no qual somente duas estações climáticas são bem definidas (verão e inverno), ocorre um fenômeno conhecido como vazante, em que as chuvas diminuem drasticamente, causando o rebaixamento do nível das águas, e consequentemente dificultando o transporte fluvial no período de seca, que vai de julho a início de novembro. (PINTO et al., 2011, p.5).

Conforme o estabelecido nas Normas da Autoridade Marítima para navegação e cartas náuticas (NORMAM-28/DHN), ao percorrer a bacia Amazônica os navios estão navegando em áreas restritas, o que exige cuidados adicionais com a segurança da navegação.

"Serviço de Praticagem é o conjunto de atividades profissionais de assessoria ao Comandante, requeridas por força de peculiaridades locais que dificultem a livre e segura movimentação da embarcação." (Normas da Autoridade Marítima para o serviço de praticagem - NORMAM-12/DPC).

Prático é aquele que presta serviços de praticagem. A praticagem em toda a bacia Amazônica é compulsória para os navios gaseiros da frota. De acordo com o Conselho Nacional de Praticagem - CONAPRA(2021), no Brasil existem 21 zonas de praticagem (ZP), divididas por área geográfica. O trecho Itacoatiara (AM) - Tabatinga (AM) é coberto pela ZP-2, enquanto o trecho Fazendinha (AP) - Itacoatiara (AM) é de responsabilidade da ZP-1.

Considerando o escoamento do Polo Urucu, a vazante da bacia Amazônica traz grandes problemas e desafios à navegação, principalmente no trecho Coari-Manaus. 
Além da redução dos níveis do rio, os principais riscos à navegação neste trecho são os bancos de areia, as terras caídas e ilhas que surgem numa estação e estão submersas em outra.

Pinto (2011), baseado em estudos da Administração das Hidrovias da Amazônia Ocidental (AHIMOC), enumera os fatores que dificultam a navegação no rio Solimões:

a) Erosão das margens dos rios; b) Sedimentação no leito do rio; c) Formação de bancos de areias; d) Estreitamento do canal; e) Diminuição da profundidade do canal decorrente de sedimentação; f) Fechamento do canal em alguns trechos do rio; g) Pedrais não sinalizados; h) Presença de troncos de árvores dentro do canal. (PINTO, 2011, apud PETCON, 2002).

A cada cheia anual, os bancos de areia, bem como boa parte do relevo de superfície e submerso, mudam de lugar aumentado o custo de produção de uma carta náutica. Sem a carta náutica atualizada (ferramenta essencial para qualquer navegação), por força da necessidade logística, práticos e comandantes de navios precisam atravessar os trechos críticos expostos aos riscos de se navegar em um trecho "novo" a cada ano.

Conforme o Plano Hidroviário Estratégico, elaborado pelo Ministério dos Transportes:

O rio Solimões apresenta profundidades adequadas para a navegação comercial durante todo o ano no trecho entre as cidades de Manaus (AM) e Coari (AM). No entanto, a presença de bancos de areia móveis nesse trecho pode resultar em algumas limitações de profundidade, principalmente no período de vazante do rio, restringindo o calado a até 4,0 m. (MINISTÉRIO DOS TRANSPORTES, 2013).

A correnteza do rio, ao erodir as margens, causa o que chamamos de "terras caídas”. O Ministério da Infraestrutura (2016), explica que com a queda dos barrancos, árvores de grande porte, toras e galhadas, podem cair no rio e serem arrastadas pela correnteza.

Os pontos críticos no rio Solimões para os navios gaseiros nos últimos anos são Ilha Trocari e Ilha Juçara.

"Balizamento é o conjunto de regras aplicadas aos sinais fixos e flutuantes, visando indicar as margens dos canais, as entradas dos portos, de rios, ou de qualquer 
via navegável, além de delimitar as áreas perigosas ou perigos isolados." (CLUBE DO ARRAIS, 2015). O balizamento auxilia na navegação, aumentando a segurança. Dentre outras funções, o balizamento serve para mostrar ao comandante e ao prático onde estão os limites navegáveis do canal. A despeito de sua importância no escoamento de cargas da região, grande parte do curso do rio Solimões não é balizado e a sinalização praticamente inexiste.

A Diretoria de Hidrografia e Navegação da Marinha (DHN) é a responsável pela emissão das cartas náuticas. Em 2015, a Marinha do Brasil lançou o Projeto Cartografia da Amazônia para criar e atualizar as cartas náuticas da região. Segundo a Marinha do Brasil (2015), para atualização cartográfica do rio Solimões, o projeto conta com a embarcação Aviso Hidroceanográfico Fluvial Solimões. O AvHoFlu Solimões, como é chamado, é um navio de pequeno porte, com casco em formato adequado às operações em áreas fluviais e completamente equipado para o serviço de mapeamento.

A emissão das cartas náuticas é um trabalho técnico, muito complexo e de alto custo. A imensidão da bacia Amazônica é um grande complicador. Os rios são muito extensos e dificultam o trabalho de mapeamento. Além disso, as constantes mudanças dos bancos de areia tornam a atualização das cartas uma tarefa árdua. $\mathrm{O}$ leito do rio muda de uma estação para outra. Esta é uma das razões para as cartas náuticas do trecho Coari-Manaus serem limitadas e estarem desatualizadas.

Navegar com cartas náuticas desatualizadas é um pesadelo para práticos, comandantes e companhias seguradoras de navios. Há momentos em que o comandante se vê navegando por trechos onde, devido à falta de atualização, na carta náutica original consta como sendo navegável, mas nos dias de hoje é de terra firme, ou vice-versa. Diante deste problema, as empresas de praticagem realizam sondagens com recursos próprios para atualizar suas próprias cartas, as quais não são disponibilizadas para o mercado.

A vazante da bacia Amazônica diminui consideravelmente o nível das águas (profundidades) em toda sua extensão. Dados da praticagem Proa Manaus, mostram que o nível do rio em Coari baixou de 16,34 metros em 01/08/2020, para 6,18 metros 
em 02/10/2020. O que significa uma redução de 10,16 metros do nível do rio em praticamente dois meses.

O cálculo da quantidade de GLP a ser carregado no TA-Coari depende das características de cada navio, mas, em linhas gerais, leva em conta o calado e a folga abaixo da quilha. O calado dos gaseiros da região varia entre 5 e 6,8 metros.

De acordo com as Normas da Autoridade Marítima para implantação e operação de sistemas para determinação de folga dinâmica abaixo da quilha (NORMAM33/DPC), a folga abaixo da quilha (FAQ) - traduzida do inglês, under keel clearance (UKC), é a distância entre o fundo do canal e o ponto mais baixo da quilha do navio. É a margem de segurança que o navio tem para evitar encalhar ou mesmo se chocar com o fundo, ou com objetos no fundo.

Figura 3 - Nível do Rio Solimões entre 01/08/2020 e 02/10/2020

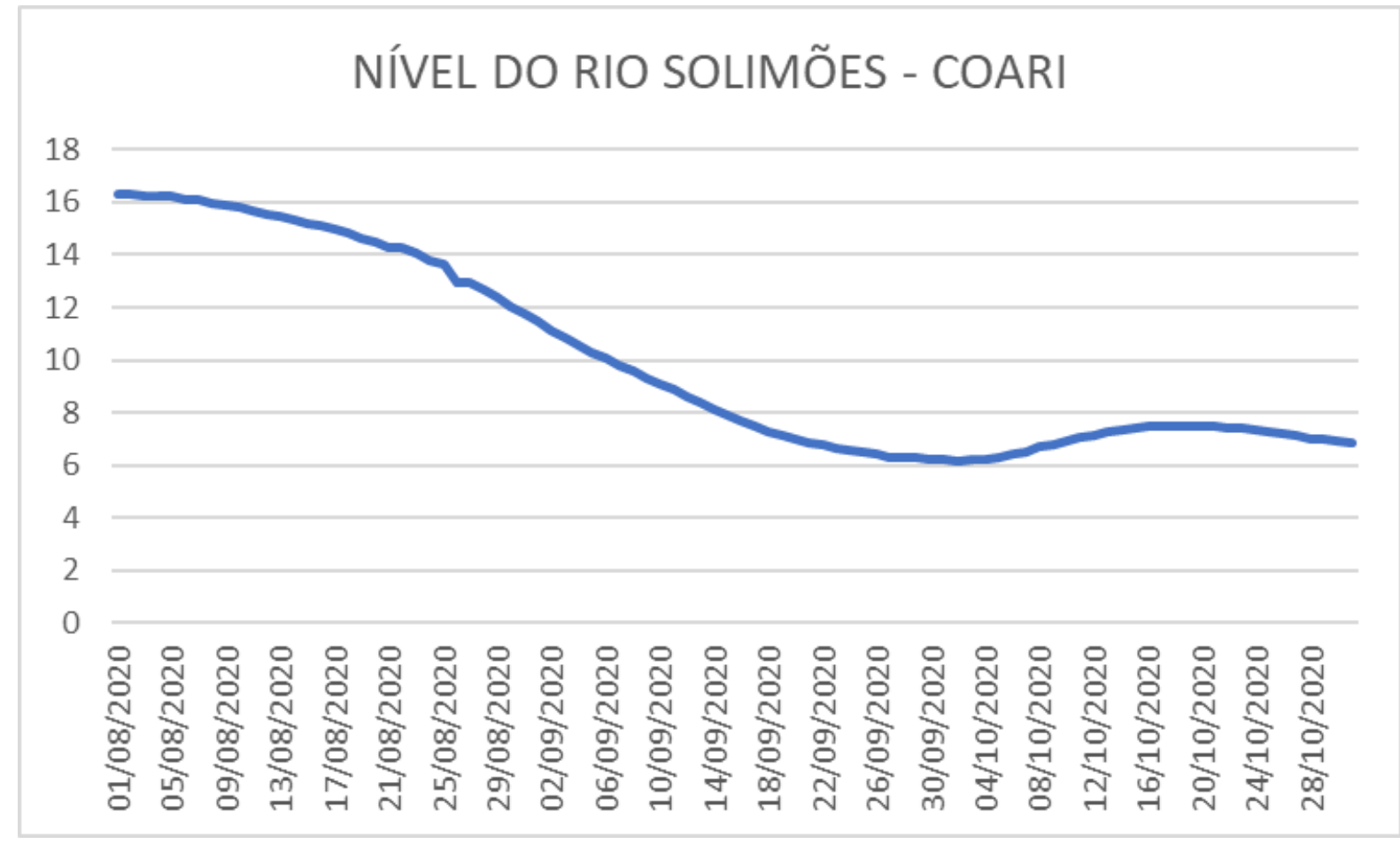

Fonte: elaboração própria, com dados de Proa Manaus (2021)

Nos trechos críticos, a velocidade é reduzida para minimizar o efeito squat e não ocasionar redução na folga abaixo da quilha. O efeito squat (afundamento) é a diminuição da folga abaixo da quilha causada por um efeito hidrodinâmico que é 
diretamente proporcional à velocidade do navio e inversamente proporcional à profundidade do canal. Ou seja, quanto maior a velocidade, maior o squat. Quanto mais raso for o canal, maior o squat. Logo, em tempos de seca, com níveis de água baixos, a velocidade do navio é reduzida para mitigar tal efeito e a consequente diminuição da folga abaixo da quilha, o que ameaça a segurança da navegação. Entretanto, quando o navio navega a favor do rio, ou seja, descendo a correnteza, este efeito dificulta a manobrabilidade e o governo fica prejudicado podendo o navio ser lançado contra a margem do rio. Para minimizar os efeitos da correnteza passando pela popa do navio, garantindo algum governo, é necessário um aumento da velocidade. Temos um conflito de decisão na escolha da velocidade ideal: reduzir o squat versus manobrabilidade.

A Capitania Fluvial da Amazônia, com base na Lei 9.537/1997, pode restringir a navegação em determinados trechos, estabelecendo calados e folga abaixo da quilha mínimos, caso o nível do rio baixe a ponto de colocar em risco a segurança das embarcações.

A vazante da bacia Amazônica também afeta a navegação no trecho ManausFoz do rio Amazonas. Há vários pontos de atenção no rio Amazonas, mas historicamente, a Ponta do Tabocal, a $44 \mathrm{~km}$ de Manaus, é o ponto mais crítico, com o nível do rio Amazonas chegando a níveis alarmantes, mesmo para navios de baixo calado.

O trecho compreendido entre o TA-Coari até a região do porto de Itacoatiara, a 111 milhas náuticas de Manaus, é de praticagem obrigatória. Dois práticos se revezam na tarefa de assessorar o comandante na navegação.

Todo o trecho de Manaus até a Foz do rio Amazonas é bem sinalizado, balizado e com cartas náuticas atualizadas.

Em Itacoatiara, ocorre a troca dos práticos, sendo substituídos por dois outros, que desembarcam em Fazendinha (AP).

A Barra Norte é um canal localizado na foz do rio Amazonas. É considerado um ponto crítico para navios de maior calado e exige uma navegação de alta precisão devido aos bancos de areia e ao arco lamoso, que compreende um percurso de 20 milhas. 
A praticagem no trecho que vai de Fazendinha até o ponto de prático de Espadarte, próximo ao estuário do rio Pará, é facultativa e o comandante devidamente habilitado pela autoridade marítima pode optar por navegar sem prático, mas desta forma assumindo os riscos de acidentes e suas consequências. A praticagem de Espadarte até o porto de Belém é obrigatória e coberta pela ZP-03. A praticagem de Espadarte até o canal de acesso ao porto de Itaqui é opcional, sendo obrigatória a partir deste ponto.

\section{O PLANO DE CONTINGÊNCIA PARA A VAZANTE DA BACIA AMAZÔNICA}

O plano de contingência é um grande e minucioso projeto, concebido para minimizar as consequências do período de estiagem da bacia Amazônica na logística de escoamento da produção do Polo Urucu.

Espera-se que as menores profundidades dos trechos críticos do rio Solimões ocorram entre os meses de setembro e outubro. Entretanto, no início de cada ano, o plano é concebido e validado visando garantir o cumprimento de todas as etapas antes do início da estiagem. A validação ocorre mediante a realização de um simulado, onde são apontadas as falhas e correções antes de um possível acionamento da contingência.

São dois os gatilhos que podem iniciar o plano de contingência: o estoque mínimo das tancagens de GLP e o nível mínimo do rio.

O planejamento da frota considera a frota mínima necessária para o escoamento de GLP durante a vazante. A análise leva em conta a necessidade de contratação de navios de baixo calado. Caso não estejam disponíveis na frota, contratam-se para cobrir o período da estiagem.

A equipe de programação deve garantir que a frota destacada para a contingência esteja posicionada na região Norte no período crítico.

A equipe de operação de navios deve diligenciar para que os navios destacados para a contingência estejam disponíveis, posicionados, prontos para operar, com tripulação experiente, munidos de todas as cartas náuticas disponíveis da região e toda documentação necessária para a operação. 
Os navios envolvidos na contingência devem ter prioridade nas filas de operações dos terminais e nos abastecimentos.

As manutenções preventivas das esferas e dos píeres devem ser programadas para ocorrerem fora do período de estiagem. No caso de necessidade imperativa de manutenções corretivas, no período crítico, todos os esforços devem ser envidados para que elas sejam concluídas no menor tempo possível. Durante a contingência, os terminais devem estar preparados, com os seus berços prontos para uso. As esferas devem estar disponíveis em suas capacidades máximas.

Devido à drástica redução dos níveis do rio Solimões, a navegação até Coari fica restrita a navios menores. Para garantir o escoamento de GLP, ao ser acionado o plano de contingência, transbordos navio-a-navio são realizados na margem oposta à cidade de Codajás, localizada na margem esquerda do rio, a 70 milhas náuticas de Coari. Navios de menor calado passam a fazer o trecho Coari-Codajás, descarregando para navios maiores, que seguirão suas programações navegando pelos trechos mais profundos em direção ao mar.

Para serem realizadas as operações de transbordos navio-a-navio e entre naviobarcaças, são necessárias autorizações da Marinha do Brasil e do órgão ambiental. As autorizações são as seguintes:

- autorização emitida pelo órgão ambiental do Governo do Estado do Amazonas, através do Instituto de Proteção Ambiental do Amazonas - IPAAM;

- "Nada a Opor" da Autoridade Marítima para operação de transbordo, emitido pela Capitania Fluvial da Amazônia Ocidental, subordinada à Marinha do Brasil.

Para realizações dos transbordos é necessária a contratação de embarcações de apoio, tais como rebocadores, lanchas de amarração, lanchas para transporte de pessoal, balsas para transporte de material de apoio e embarcações alojamento.

Para serem autorizadas a operar, todas as embarcações devem ser devidamente inspecionadas por oficiais da Marinha Mercante experientes e atualizados com as normas nacionais e internacionais ligadas à atividade marítima, chamados inspetores náuticos. 
Os equipamentos necessários à realização dos transbordos devem estar à disposição quando do início da contingência. Os mangotes passam por testes hidrostáticos e as defensas por testes pneumáticos, anualmente, sendo certificados por empresas credenciadas. Outros materiais usados na operação como cabos de amarração, juntas e parafusos são conferidos, separados e colocados à disposição numa balsa de suporte à contingência, que fica estacionada em Codajás até o seu término.

Pela natureza da contingência, é imprescindível a participação de pessoal qualificado e familiarizado com a operação, em todas as funções. Em especial, é solicitado aos armadores dos navios que indiquem comandantes experientes e tripulação familiarizada com as operações de transbordo navio-a-navio.

Uma equipe de contingência deve ser destacada para acompanhar de perto as operações de transbordo. Uma balsa contendo material para combate à poluição e incêndio é posicionada na cidade de Codajás, de prontidão para qualquer emergência.

Devido à pandemia da covid-19, embarcações alojamento são disponibilizadas para dar hospedagem ao pessoal operacional, evitar o deslocamento para a cidade de Codajás e manter o isolamento social.

\section{DESAFIOS DO TRANSPORTE DE GLP DURANTE A VAZANTE DA BACIA AMAZÔNICA}

A imprevisibilidade da natureza e a falta de informações são os principais desafios ao transporte de GLP durante a estiagem da bacia Amazônica. Um dos gatilhos que disparam o plano de contingência é a redução de profundidade nos trechos críticos, que historicamente chega a níveis mínimos entre setembro e outubro, período em que mesmo navios menores, podem não conseguir atravessá-los, obrigando a uma redução da quantidade a ser carregada, com consequente redução do calado e aumento da margem de segurança para navegar em tais trechos. $\mathrm{O}$ monitoramento constante é a chave para uma tomada de decisões segura. No entanto, ao longo dos anos ficou evidente a dificuldade em obter da autoridade marítima informações oficiais, principalmente sobre o rio Solimões. Diante da falta de 
informação, a equipe de operação de navios recorre a alternativas para ter algumas medições, mesmo que não oficiais. As réguas de medição de profundidade instaladas nos terminais de Coari e Manaus fornecem medições confiáveis, mas nada informam sobre os trechos críticos da logística de escoamento de GLP do rio Solimões (Ilha Trocari - Ilha Juçara/Abacate). Assim, numa tentativa de obter tais informações, solicitam-se aos navios da frota designados para a região que realizem medições em determinados trechos do rio. A análise destas medições é restrita, haja vista que são realizadas tanto na ida quanto na volta, mas somente nos canais navegados pelos práticos de cada praticagem e que não são necessariamente os mesmos. Assim, não é feita uma varredura completa dos pontos críticos. A equipe de operação de navios também monitora os índices pluviométricos à montante de Coari. Chuvas na Amazônia peruana podem indicar o aumento dos níveis dos rios à jusante. Este monitoramento é de grande utilidade, porém é uma tarefa difícil. Mais uma vez, não há informações oficiais e os dados disponíveis são fragmentados.

A falta de cartas náuticas atualizadas é um grande problema para a navegação, na medida em que expõem os navios a risco de acidentes como encalhe e poluição em um local de meio-ambiente sensível e de grande visibilidade mundial. Além disso, para a população local - os ribeirinhos, o rio é a única via de transporte de pessoas e suprimentos. Um encalhe poderia significar o fechamento do tráfego naquele trecho, prejudicando a população e economia locais. Para mitigar estes riscos, a tendência natural é aumentar a folga abaixo da quilha e diminuir a quantidade transportada, o que implica em custos maiores e ocorrência de frete morto.

A realização de sondagens por iniciativa própria, ou mesmo a contratação de batimetrias realizadas pelas empresas de praticagem, serve como um paliativo. Porém, a solução definitiva depende de a autoridade marítima realizar os mapeamentos e atualizar as cartas náuticas. A indisponibilidade de recursos é um empecilho ao sucesso do plano. As operações de transbordo constituem um desafio logístico pela complexidade e pelo número de variáveis envolvidas. Navios, terminais, equipamentos de apoio, praticagem, grupos de operação e de apoio precisam estar prontos para entrar em ação no início da contingência. Ter todos esses recursos disponíveis requer um grande trabalho de diligenciamento, pois nunca se sabe com 
grande antecedência quando o nível do rio atingirá níveis críticos que darão início à contingência.

A indefinição quanto à $F A Q$ a ser adotada durante o período de vazante interfere na escolha dos navios a serem mobilizados para a operação, no cálculo das quantidades a serem transportadas e no gatilho do plano de contingência. Cada armador adota uma política para a FAQ, mas conforme as Normas da Autoridade Marítima para implantação e operação de sistemas para determinação de folga dinâmica abaixo da quilha (NORMAM-33/DPC), a determinação da folga mínima em trechos de área restrita é de responsabilidade das autoridades marítimas. Baseado no calado e na folga abaixo da quilha, calcula-se o nível mínimo do rio para operação segura. No entanto, devido à falta de cartas náuticas atualizadas e as incertezas da navegação nos pontos críticos, a praticagem por vezes aumenta a exigência de FAQ. Para manter o nível mínimo, a saída é diminuir a quantidade de carga, o que significa uma menor eficiência e um custo maior.

Os transbordos são necessários para que navios menores, que conseguem navegar em trechos com profundidade menor, transfiram sua carga para navios maiores, com restrições de calado durante o período de estiagem. Uma solução alternativa a ser considerada é o uso de navios de baixo calado, porém com maior capacidade de carga. Outra opção seria a contratação de barcaças de GLP, porém há pouquíssima disponibilidade na região. Além de não serem afetadas pelos baixos níveis do rio na vazante, as barcaças de GLP dariam maior flexibilidade às operações.

A pandemia do coronavírus trouxe grandes preocupações para o transporte marítimo. Protocolos foram implementados por agências reguladoras, armadores, operadores logísticos, etc., para prevenir a contaminação dos envolvidos. Inevitavelmente, o cumprimento de todos esses protocolos implica atrasos na operação.

A ANVISA estabeleceu procedimentos para embarque e desembarque de tripulantes em navios. Dentre várias medidas, a agência estipula que antes de embarcar, o tripulante deve cumprir quarentena de 14 dias em casa ou em um hotel. A livre prática é um documento emitido pela ANVISA atestando as condições operacionais e higiênico-sanitárias do navio, assim como do estado de saúde dos 
seus viajantes, liberando-o a operar. Caso o comandante relate a suspeita de tripulante infectado, a ANVISA inicialmente não emitirá a livre prática. Isso significa que o navio não poderá operar e nem desembarcar ninguém naquele porto, até que um inspetor-médico vá a bordo e avalie o(s) tripulante(s). Se a suspeita for confirmada, o(s) tripulante(s) será(ão) desembarcado(s) para atendimento médico e o navio entrará em quarentena. Ou seja, o navio estará fora de operação por no mínimo 14 dias.

A maioria das empresas de navegação estabeleceu planos de gerenciamento do surto de covid-19. O comandante é o representante do armador e a autoridade máxima no navio. Portanto, ele deve cumprir os procedimentos para prevenir a contaminação, isolar os tripulantes suspeitos de contágio e transferir os infectados. Cada navio possui áreas para isolamento dos tripulantes suspeitos de contágio, que devem cumprir quarentena de 14 dias. Os tripulantes comprovadamente infectados são desembarcados.

\section{CONCLUSÃO}

Por se tratar de planejamento logístico em local ambientalmente sensível e acossado continuamente por imprevisíveis fenômenos da natureza, ele é único, crítico e deve ser revisado a cada ano num processo de melhoria contínua. A logística envolvida para minimizar os riscos de uma parada de produção não planejada e o desabastecimento dos mercados consumidores requer muito planejamento $\mathrm{e}$ diligenciamento das ações.

As ações para monitorar os níveis dos rios e os estoques de GLP, acompanhar as previsões e ocorrências de chuvas na região, manter todos recursos prontos a operar a qualquer momento e todas as áreas envolvidas informadas, demandam um grande esforço.

A falta de informações oficiais por parte das autoridades marítimas potencializa os problemas e exige ações alternativas. Com a incerteza, a navegação se torna mais lenta, as restrições ao carregamento crescem, as quantidades carregadas nos navios diminuem, os estoques caem e os custos aumentam. 
Os desafios do transporte de GLP durante a vazante da Bacia Amazônica envolvem problemas logísticos e estruturais.

Em uma região onde o modal hidroviário é o principal meio de transporte e o período de estiagem representa um gargalo para o escoamento de um dos maiores campos de produção terrestre de petróleo do país, faltam ações do Estado para garantir uma mínima infraestrutura que garanta uma navegação segura.

A execução do plano de contingência aponta para várias soluções, porém algumas das mais importantes dependem de ações das autoridades marítimas. Não há o que fazer sobre a ausência de sinalização e balizamento do rio Solimões, a não ser cobrar das autoridades competentes. O mesmo vale para as atualizações das cartas náuticas. Uma parceria e maior interação entre Petrobras, Marinha do Brasil e empresas de praticagem pode render boas soluções para estes antigos problemas.

Diante das incertezas, o transporte marítimo de GLP durante a vazante da Bacia Amazônica é uma atividade de alto risco. Os desafios são muitos e os custos envolvidos são altos. Não há margem para erros.

\section{REFERÊNCIAS BIBLIOGRÁFICAS}

AGÊNCIA BRASIL (2016) - Urucu completa 30 anos de exploração de petróleo em plena Amazônia. Disponível em: https://agenciabrasil.ebc.com.br/economia/noticia/ 2016-12/urucu-completa-30-anos-de-exploracao-de-petroleo-em-plena-amazonia. Acesso em: 28 dez. 2020.

AGÊNCIA NACIONAL DE ÁGUAS E SANEAMENTO BÁSICO - ANA (2021). Disponível em: https://www.gov.br/ana/pt-br/assuntos/gestao-das-aguas/panoramadas-aguas/regioes-hidrograficas/regiao-hidrografica-amazonica. Acesso em: 05 Jan. 2021.

AGÊNCIA NACIONAL DE TRANSPORTES AQUAVIÁRIOS - ANTAQ (2021). Disponível em: http://web.antaq.gov.br/portalv3/PNIH/RTBaciaAmazonica.pdf. Acesso em: 21 Jan. 2021.

AGÊNCIA PETROBRAS (2020). Disponível em: https://www.agenciapetrobras.com.br/Materia/ExibirMateria?p_materia $=982958$. Acesso em: 28 dez. 2020. 
ÁVILA, Marcelo; OLIVEIRA-JUNIOR, Ernandes; REIS, Mariana; HESTER, Eric; DIAMANTINO, Cristiane; VERAART, Annelies; LAMERS, Leon; KOSTEN, Sarian; NASCIMENTO, Andréa. (2019) The Water Hyacinth Microbiome: Link Between Carbon Turnover and Nutrient Cycling. Journal Microbial Ecology, 78. (2019).

CLUBE DO ARRAIS. Curso de Arrais Amador. 2015. Disponível em: https://www.clubedoarrais.com/curso-de-arrais-amador-sinalizacaonautica/\#: :text=Clube\%20do\%20Arrais.-,BALIZAMENTO,\%C3\%A1reas\%20perigos as\%20ou\%20perigos\%20isolados. Acesso em: 07 jan. 2021.

CONSELHO NACIONAL DE PRATICAGEM - CONAPRA (2021). Disponível em: https://www.praticagemdobrasil.org.br/praticagem/zonas-de-praticagem/. Acesso em: 18 jan. 2021.

FISCH, Gilberto; MARENGO, José; NOBRE, Carlos. Clima da Amazônia. Centro de Previsão de Tempo e Estudos Climáticos (CPTEC/INPE). 2020. Disponível em: http://climanalise.cptec.inpe.br/ rclimanl/boletim/cliesp10a/fish.html. Acesso em: 26 dez. 2020.

FRAXE, Therezinha; PEREIRA, Henrique; WITKOSKI, Antônio. A dinâmica da paisagem socioambiental das várzeas do rio Solimões-Amazonas. In: Comunidades ribeirinhas amazônicas: modos de vida e uso dos recursos naturais. Cap. 1. (pp.11 - 32). Ed. 1. Manaus: EDUA, 2007.

LEI 9.537, DE 11 DE DEZEMBRO DE 1997. Disponível em: http://www.planalto.gov.br/ccivil_03/leis/19537.htm. Acesso em: 20 dez. 2020.

PINTO, Luis; LEE, Jun; JONQUA, Julien. A importância do transporte fluvial para a unidade operacional da Amazônia. In: XXXI Encontro Nacional de Engenharia de Produção - Inovação Tecnológica e Propriedade Intelectual: Desafios da Engenharia de Produção na Consolidação do Brasil no Cenário Econômico Mundial. Belo Horizonte, 4 a 7 de outubro de 2011.

MARINHA DO BRASIL. Projeto Cartografia da Amazônia. 2015. Disponível em: https://www.marinha.mil.br/dhn/chm/sites/www.marinha.mil.br.dhn/files/arquivos/Navi os $\% 20$ oriundos\%20do\%20Proj.Cartografia\%20da\%20Amaz\%C3\%B4nia.pdf. Acesso em: 21 jan. 2021.

MINISTÉRIO DOS TRANSPORTES. Relatório do Plano Hidroviário Estratégico, 2013. Disponível em: http://antigo.infraestrutura.gov.br/images/TRANSPORTE HIDROVIARIO/PHE/RELATORIO_PLANO_ESTRATEGICO.pdf. Acesso em: 13 jan. 2021.

MINISTÉRIO DA INFRAESTRUTURA. DNIT contrata estudos e projeto contra acúmulo de toras e galhos em Instalações Portuárias de Pequeno Porte. 2016. Disponível em: https://www.gov.br/infraestrutura/pt-br/assuntos/noticias/ultimas- 
noticias/dnit-contrata-estudos-e-projeto-contra-acumulo-de-toras-e-galhos-eminstalacoes-portuarias-de-pequeno-porte. Acesso em: 02 jan. 2021.

NORMAM-12/DPC - DIRETORIA DE PORTOS E COSTAS (DPC) - MARINHA DO BRASIL - NORMAS DA AUTORIDADE MARÍTIMA PARA O SERVIÇO DE PRATICAGEM. Disponível em: https://www.marinha.mil.br/dpc/sites/www.marinha. mil.br.dpc/files/processo-selecao/normam12.pdf. Acesso em: 15 dez. 2020.

NORMAM-28/DPC - DIRETORIA DE PORTOS E COSTAS (DPC) - MARINHA DO BRASIL - NORMAS DA AUTORIDADE MARÍTIMA PARA NAVEGAÇÃO E CARTAS NÁUTICAS. Disponível em: https://www.marinha.mil.br/dhn/?q=pt-br/node/267. Acesso em: 19 dez. 2020.

NORMAM-33/DPC - DIRETORIA DE PORTOS E COSTAS (DPC) - MARINHA DO BRASIL - NORMAS DA AUTORIDADE MARÍTIMA PARA IMPLANTAÇÃO E OPERAÇÃO DE SISTEMAS PARA DETERMINAÇÃO DE FOLTA DINÂMICA ABAIXO DA QUILHA. Disponível em: https://www.marinha.mil.br/dhn/?q=ptbr/node/267. Acesso em: 12 jan. 2021.

PROA MANAUS (2021). Disponível em: http://proamanaus.com.br/?u=regua-dosrios\&mes=10\&ano=2020. Acesso em: 03 jan. 2021.

SALATI, Eneas; MARQUEZ, José; MOLION, Luiz. Origem e distribuição das chuvas na Amazônia. Revista Interciência, v.3, n.4, p.200-205, 1978.

TRANSPETRO (2020). Disponível em: http://transpetro.com.br/lumis/portal/file/ fileDownload.jsp?fileld=8A9D2A7C7547D113017691640EE96237. Acesso em: 26 dez. 2020.

TRANSPETRO (2021). Disponível em: http://transpetro.com.br/transpetroinstitucional/nossas-atividades/dutos-e-terminais/terminais-aquaviarios/belempa.htm. Acesso em: 04 Jan. 2021.

TRANSPETRO (2021a). Disponível em: http://transpetro.com.br/transpetroinstitucional/nossas-atividades/dutos-e-terminais/terminais-aquaviarios/sao-luisma.htm. Acesso em: 04 Jan. 2021. 